\title{
Penetrating Trauma Resulting in Ventricular Septal Defect
}

\author{
Daniel Juneau, Daniel Hermann, *Gretchen L. Wells \\ Wake Forest School of Medicine, Department of Internal Medicine, Section on Cardiology, Winston-Salem, USA \\ Email: "gwells@wakehealth.edu
}

Received 27 March 2014; revised 27 April 2014; accepted 5 May 2014

Copyright (C) 2014 by authors and Scientific Research Publishing Inc.

This work is licensed under the Creative Commons Attribution International License (CC BY).

http://creativecommons.org/licenses/by/4.0/

(c) (i) Open Access

\begin{abstract}
Most ventricular septal defects (VSDs) are congenital. Acquired VSDs are generally due to myocardial infarction. An unusual case of VSD from penetrating trauma is described. In this case, the lack of a hemopericardium at presentation led the treatment team not to pursue cardiac pathology. Once the patient developed heart failure, the diagnosis of a VSD was made. Patients with penetrating chest wounds should undergo echocardiography, as such lesions may not be detected by physical examination or chest exploration.
\end{abstract}

\section{Keywords}

\section{Ventricular Septal Defect, Penetrating Trauma, Echocardiography}

\section{Introduction}

Penetrating cardiac injuries are usually due to stabbing or gunshot wounds. These injuries may result in serious conditions, including hemorrhage, pericardial tamponade, damage to the conduction system, and laceration of a coronary artery [1] [2]. Overall survival rates as low as 33 percent have been reported, with considerably higher survival rates in stabbing victims compared to those sustaining gunshot wounds [3]. While many penetrating cardiac injuries are acutely life-threatening, some lead to delayed long-term sequelae including valvular defects, ventricular aneurysm, pericardial effusion, and ventricular septal defect (VSD). Such lesions occur in up to 17 percent of patients and may not be clinically evident upon initial evaluation [2] [4] [5]. Here we describe a patient who acquired a VSD from a stab wound to the anterior chest. He gradually developed symptoms of heart failure over the following seven months, at which time the lesion was repaired.

*Corresponding author. 


\section{Case Presentation}

A 45-year-old male presented to an Emergency Department following a stab wound twice in the anterior chest. The patient sustained a 1-cm puncture wound in the left parasternal region at the third intercostal space, and a 1-cm stab wound at the left anterior axillary line at the level of the second intercostal space. On arrival, he was fully conscious and hemodynamically stable, with a heart rate of 89 beats/min, blood pressure $138 / 70 \mathrm{~mm} \mathrm{Hg}$, and a respiratory rate of 24 breaths/min. Auscultation revealed decreased breath sounds over the left chest, but no cardiac murmur. The upper extremities had strong pulses and equal blood pressure bilaterally. Chest CT demonstrated a moderately sized left hemothorax, a large mediastinal hematoma measuring $7.7 \times 3.0 \mathrm{~cm}$, and a possible small hemopericardium.

Given the concern for cardiac injury, the patient was transferred to the operating room, where a left-sided chest tube was placed and a pericardial window was performed Division of the pericardium revealed clear fluid, but no blood in the pericardial sac. The patient had an unremarkable post operative course and was discharged to home one week later.

The patient was readmitted two days later with transient visual loss. A grade 4/6 systolic murmur was now heard on auscultation. An echocardiogram was performed to evaluate for etiology of embolic stroke. This study demonstrated a nonrestrictive muscular VSD (Figure 1) at the proximal septum with a gradient of $36 \mathrm{~mm} \mathrm{Hg}$ (Figure 2). Estimated right ventricular systolic pressure was $>60 \mathrm{~mm} \mathrm{Hg}$, with mild tricuspid regurgitation. The LV ejection fraction was 55\% - 60\%. The estimated pulmonary to systemic blood flow ratio (Qp/Qs) was 3.0. The patient was acyanotic and reported no knowledge of a heart murmur. An echocardiogram performed at an outside facility in 1994 was reviewed and did not show evidence of a VSD.

With the diagnosis of penetrating traumatic VSD, the patient initially remained asymptomatic, and was treated conservatively at his request. He later developed heart failure characterized by exercise intolerance, shortness of breath, orthopnea, and paroxysmal nocturnal dyspnea and underwent surgical repair with a bovine pericardial patch via a right ventriculotomy. The patient did well following surgery and was discharged to home on post operative day seven.

\section{Discussion}

VSDs following penetrating cardiac trauma are uncommon but not rare, occurring in five percent of cases. In the setting of trauma, multiple factors can distract the clinician away from the diagnosis of VSD [6]. Patients sustaining penetrating cardiac injury usually present with either cardiac tamponade or hemothorax and hypotension [7]. Therefore, stabilization of the patient and treatment of more obvious injuries are addressed first. In our case, treatment of the patient's hemothorax took priority. Our patient did not initially have a precordial murmur on examination. In a study of ten patients with intracardiac shunts from penetrating trauma, five out of ten did not have a cardiac murmur on initial evaluation but developed a murmur one to 21 days after injury. The authors

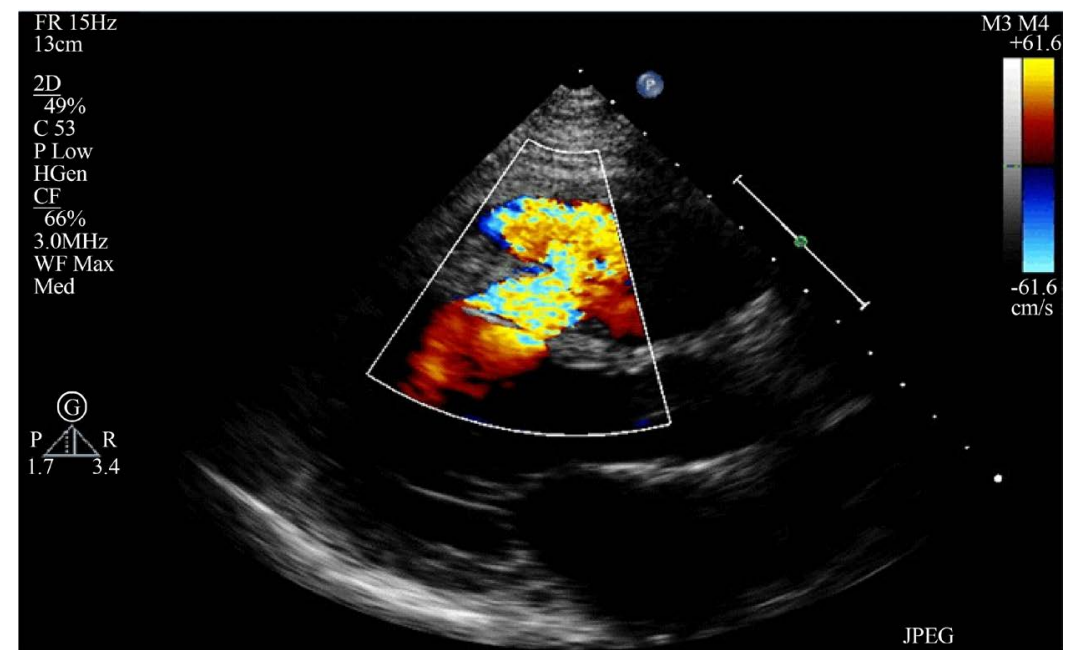

Figure 1. Transthoracic echocardiogram-parasternal long axis view demonstrating muscular VSD by color flow Doppler. 


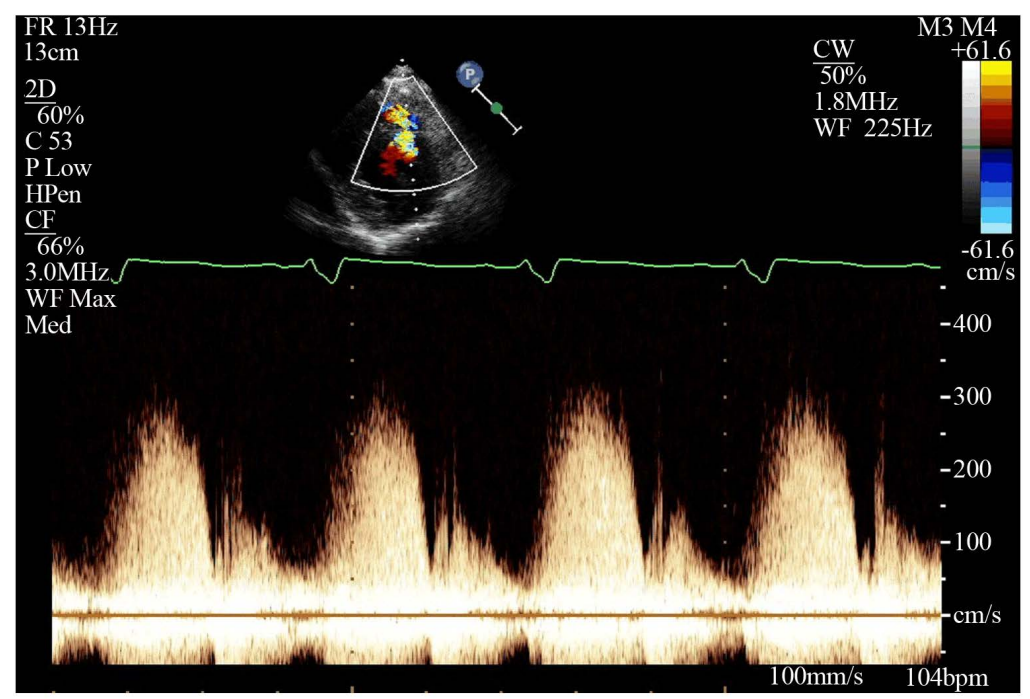

Figure 2. Transthoracic echocardiogram-continuous wave Doppler demonstrating $3 \mathrm{~m} / \mathrm{sec}(36 \mathrm{~mm} \mathrm{Hg}$ ) gradient of nonrestrictive VSD.

suggest that penetrating trauma can create an area of weakness in the septum that can subsequently rupture to form a clinically significant fistula [7]. This may have been the case in our patient, who lacked a murmur during his initial hospital admission, but developed one between discharge and readmission, seven to nine days after the injury.

Interestingly, our patient acquired a VSD from penetrating trauma but did not have a hemopericardium. The lack of this finding directed the treatment team away from further evaluation of intracardiac pathology. Reports have indicated that small pericardial effusions can indicate the presence of VSDs following penetrating chest injuries [8]. Therefore, without clear evidence of hemopericardium or cardiac tamponade, VSD may not be considered in the differential diagnosis. However, including our case, there have been three reported cases of VSDs resulting from penetrating cardiac trauma without hemopericardium [6] [9]. Thus, the lack of a pericardial effusion does not rule out penetrating cardiac injury or formation of a VSD. One possible mechanism of penetrating injury without hemopericardium is a small wound $(0.5 \mathrm{~cm}$ to $1.0 \mathrm{~cm})$ that seals spontaneously due to ventricular spasm or clot formation [7]. Alternatively, in patients with penetrating cardiac injuries, blood from the pericardium can decompress into the ipsilateral hemithorax via adjacent lacerations in the pericardium. These patients were shown to have FAST ultrasound examinations that were negative for hemopericardium [10]. Therefore, it is plausible in our case that a penetrating wound to the chest created an opening in the pericardium that allowed drainage of blood into the pleural cavity.

Our conclusion is that when penetrating cardiac injury is suspected, echocardiography should be performed in the initial evaluation, even in patients who are hemodynamically stable. A high suspicion for intracardiac lesions should be maintained in the days to months following injury. Repeat evaluation should be considered to exclude delayed rupture of the ventricular septum [4]. To prevent congestive heart failure and pulmonary hypertension, VSDs should be repaired when the defect is large (Qp/Qs $\geq 2.0)$. Repair of smaller defects should be considered with a Qp/Qs > 1.5 in the presence of LV systolic or diastolic failure, or if the pulmonary artery pressure is less than $2 / 3$ of systemic pressure and pulmonary vascular resistance is less than $2 / 3$ of systemic vascular resistance [11]. Other patients with small VSDs and no evidence of heart failure can be managed conservatively with serial echocardiography, and in some cases small defects may even close spontaneously over time [12].

\section{References}

[1] Mulder, D.G. (1964) Stab Wound of the Heart. Annals of Surgery, 2, 287-291. http://dx.doi.org/10.1097/00000658-196408000-00017

[2] Symbas, P.N. (1974) Residual or Delayed Lesions from Penetrating Cardiac Wounds. Chest, 66, 408-410. http://dx.doi.org/10.1378/chest.66.4.408

[3] Carr, J.A., Buterakos, R., Bowling, W.M., Janson, L., Kralovich, K.A., Copeland, C., Link, R., Roiter, C., Casey, G. 
and Wagner, J.W. (2011) Long-Term Functional and Echocardiographic Assessment after Penetrating Cardiac Injury: 5-Year Follow-Up Results. The Journal of Trauma, 70, 701-704. http://dx.doi.org/10.1097/TA.0b013e31820c405a

[4] Kumar, S., Moorthy, N., Kapoor, A. and Sinha, N. (2012) Gunshot Wounds: Causing Myocardial Infarction, Delayed VSD, and Congestive Heart Failure. Texas Heart Institute Journal, 39, 129-132.

[5] Demetriades, D., Charalambides, C., Sareli, P. and Pantanowitz, D. (1990) Late Sequelae of Penetrating Cardiac Injuries. British Journal of Surgery, 77, 813-814. http://dx.doi.org/10.1002/bjs.1800770731

[6] Olsovsky, M.R., Topaz, O., Disciascio, G. and Vetrovec, W. (1996) Acute Traumatic Ventricular Septal Rupture. American Heart Journal, 131, 1039-1041. http://dx.doi.org/10.1016/S0002-8703(96)90193-3

[7] Thandroyen, F.T. and Matisonn, R.E. (1981) Penetrating Thoracic Trauma Producing Cardiac Shunts. The Journal of Thoracic and Cardiovascular Surgery, 81, 569-573.

[8] Jeon, K., Lim, W., Kang, S., Cho, I., Kim, K., Kim, H., Kim, Y. and Sohn, D. (2010) Delayed Diagnosis of Traumatic VSD in Penetrating Chest Injury: Small Evidence on Echocardiography Makes a Big Difference. Journal of Cardiovascular Ultrasound, 18, 28-30. http://dx.doi.org/10.4250/jcu.2010.18.1.28

[9] Salehian, O., Teoh, K. and Mulji, A. (2003) VSD Secondary to Penetrating Trauma without Pericardial Effusion. Canadian Journal of Cardiology, 19, 1437-1439.

[10] Ball, C.G., Williams, B.H., Wyrzykowski, A.D., Nicholas, J.M., Rozycki, G.S. and Feliciano, D.V. (2009) A Caveat to the Performance of Pericardial Ultrasound in Patients with Penetrating Cardiac Wounds. The Journal of Trauma, 67, 1123-1124. http://dx.doi.org/10.1097/TA.0b013e3181b16f30

[11] Warnes, C.A., Williams, R.G., Bashore, T.M., Child, J.S., Connolly, H.M., Dearani, J.A., del Nido, P., Fasules, J.W., Graham Jr., T.P., Hijazi, Z.M., Hunt, S.A., King, M.E., Landzberg, M.J., Miner, P.D., Radford, M.J., Walsh, E.P., Webb, G.D., Smith Jr., S.C., Jacobs, A.K., Adams, C.D., Anderson, J.L., Antman, E.M., Buller, C.E., Creager, M.A., Ettinger, S.M., Halperin, J.L., Hunt, S.A., Krumholz, H.M., Kushner, F.G., Lytle, B.W., Nishimura, R.A., Page, R.L., Riegel, B., Tarkington, L.G., Yancy, C.W., American College of Cardiology, American Heart Association Task Force on Practice Guidelines (Writing Committee to Develop Guidelines on the Management of Adults with Congenital Heart Disease), American Society of Echocardiography, Heart Rhythm Society, International Society for Adult Congenital Heart Disease, Society for Cardiovascular Angiography and Interventions and Society of Thoracic Surgeons (2008) ACC/AHA 2008 Guidelines for the Management of Adults with Congenital Heart Disease: A Report of the American College of Cardiology/American Heart Association Task Force on Practice Guidelines (Writing Committee to Develop Guidelines on the Management of Adults With Congenital Heart Disease). Developed in Collaboration with the American Society of Echocardiography, Heart Rhythm Society, International Society for Adult Congenital Heart Disease, Society for Cardiovascular Angiography and Interventions, and Society of Thoracic Surgeons. Journal of the American College of Cardiology, 52, e143-e263. http://dx.doi.org/10.1016/j.jacc.2008.10.001

[12] Ilia, R., Goldfarb, B., Wanderman, K.L. and Gueron, M. (1992) Spontaneous Closure of a Traumatic Ventricular Septal Defect after Blunt Trauma Documented by Serial Echocardiography. Journal of the American Society of Echocardiography, 5, 203-205. http://dx.doi.org/10.1016/S0894-7317(14)80555-5 